\title{
Importance of anatomist and clinician interaction
}

\author{
Anatomy 2008; 2 Suppl: 3, (c) 2008 TSACA
}

\section{Dear Colleagues,}

This year, as the organizing committee, we proposed our national anatomy congress enriched with neuroanatomy based topics and conferences. Also this year, we decided to invite an expert in his field; so as we have planned a neuroanatomy based anatomy congress, Prof. Dr. Gazi Yaşargil was the best person for this event. We all know and appreciate his special interest in anatomy. I would like to express my greatest appreciation to Mrs. Dianne Yaşargil and Prof. Dr. Gazi Yaşargil for accepting our invitation. Prof. Yaşargil showed special interest to our congress and he proposed us to invite Prof. Dr. Adgardo Angtuaco from University of Arkansas for Medical Sciences, Prof. Dr. Anton Valavanis from Institute of Neuroradiology at the University Hospital of Zurich and Prof. Dr. Uğur Türe from Yeditepe University Hospital who are all valuable scientists in their fields. I would also like to express my greatest appreciation to Prof. Angtuaco, Prof. Valavanis and Prof. Türe for their participation and conferences.

I will always feel great honour and great pleasure that my university will present "Honorary Doctorate" to Prof. Yaşargil.

Prof. Yaşargil will be giving three courses and four conferences which will be very attractive and worthwhile to both anatomists, neurosurgeons and participants from other fields. To one of his conferences, entitled "Brain Eye", all medical school students are invited to listen to Prof. Yaşargil. I can feel the excitement of our students from their feedbacks.

My sincere thanks also go to Prof. Dr. Hakan Hamdi Çelik who is the chair of the Turkish Society of Anatomy and Clinical Anatomy (TSACA) and all society members for their special efforts and support in the organization of the congress.

In this congress, we will also have the opportunity to discuss difficulties in cadaver obtaining and possible solutions. I have no doupt that discussing this issue which is vital for anatomy education will bring solutions with the participation and efforts of our valuable panelists. Here I want to express my greatest appreciation to Prof. Dr. Alaittin Elhan in his past and continuous efforts for this issue. My own opinion is that this issue should be a priority for all anatomists.

Another issue which will be discussed in the congress is novelties in teaching neuroanatomy. I would also like to express my greatest appreciation to Prof. Dr. Andreas H. Weiglein from Graz, Austria and Prof. Dr. Jürgen Koebke from Cologne, Germany who will be the panelists in this important topic.

We always discuss ethic principles in scientific publications. Are we really aware and do we really know much about this issue? I would also like to express my greatest appreciation to Prof. Dr. Şevket Ruacan who will have a presentation on these principles which shouldn't be missed.

It has been a long and hard, but pleasant organization period for all the organizing committee members and me. I would also like to thank to all members of the committee and a special thanks goes to Prof. Dr. Salih Murat Akkın for his efforts in the organization who is the former chair of TSACA.

I am sure that all participants from different fields will have the opportunity to discuss novelties in our fields and share their experiences. This is the aim of this congress; to build interactions between anatomists and clinicians.

Apart from the scientific meeting, we promise you an exciting social and cultural programme enriched with our regional tradition. We are looking forward to meeting you in a friendly and a scientifically rewarding atmosphere. It is our wish to provide participants with both scientific and cultural impressions to be long remembered by whole members of our society.

Hakan Öztürk Deputy Editor President of XII ${ }^{\text {th }}$ National Congress of Anatomy 